Journal of the Electrochemical Society, Vol. 151, No. 3, 2004, pp. B105-B113.

ISSN: (print 0013-4651)(online 1945-7111)

DOI: $10.1149 / 1.1641038$

http://scitation.aip.org/JES

http://www.ecsdl.org/getpdf/servlet/GetPDFServlet?filetype=pdf\&id=JESOAN00015100000300B105000001\&idty

pe $=$ cvips\&prog $=$ normal

(C) The Electrochemical Society, Inc. 2004. All rights reserved. Except as provided under U.S. copyright law, this work may not be reproduced, resold, distributed, or modified without the express permission of The Electrochemical Society (ECS). The archival version of this work was published in Journal of the Electrochemical Society, Vol. 151, No. 3, 2004, pp. B105-B113.

\title{
Investigation of Filiform Corrosion of Epoxy-Coated 1045 Carbon Steel by Scanning Kelvin Probe Force Microscopy
}

\author{
Patrick P. Leblanc* and G. S. Frankel ${ }^{*, z}$ \\ Fontana Corrosion Center, Department of Materials Science and Engineering, The Ohio State University,
}

\begin{abstract}
The mechanism for filiform corrosion (FFC) is thought to involve oxygen diffusion through the tail to the active head. The primary cathodic region is near the back of the head (at the head/tail boundary), where oxygen concentration is higher, and the primary anodic region is at the front edge of the head of the filament. Although there is experimental support for this mechanism, a high-resolution description of the FFC process has not been presented. The aim of this study was to provide detailed information about the mechanism of FFC on coated steel using the high spatial resolution of scanning Kelvin probe force microscopy. Segments of active filaments were successfully investigated through 150 and $300 \mathrm{~nm}$ thin epoxy coatings in air of 93\% relative humidity. Volta potential and topographic maps showed separation of active anodes and cathodes in the head and revealed the presence of voids associated with delamination of the coating along the edge of the tail. The morphology of filaments and Volta potential distributions were strongly dependent on the film thickness. Differences in growth characteristics were explained by mass transport considerations.
\end{abstract}

Filiform corrosion (FFC) affects many metals underneath organic, inorganic, or metallic coatings and results in networks of thread-like corrosion products propagating across the metal surface. Early studies of FFC focused on steel substrates coated with a variety of varnishes or lacquers. The development of new paint systems and the increased use of lightweight alloys in the aeronautical industry have widened the field of study to aluminum and magnesium alloys and to more modern coatings. FFC of steel, aluminum, and magnesium has been observed in various humidity conditions and under many different types of coatings. The growth pattern, behavior, physical dimension, and velocity of the filaments have been reviewed in detail. ${ }^{1-4}$ The literature reveals that there are many common characteristics of FFC, regardless of the nature of the metal or coating. A filament consists of two visually distinguishable parts: an active head, where dissolution of the metal occurs, and a trailing tail, composed of dry corrosion products. The interface between the dry tail and the head on iron is characterized by a V-shaped boundary. The width of filaments ranges from 0.05 to $3 \mathrm{~mm}$, and the filaments can travel considerable distances and weave intricate patterns. The average growth rate ranges between 0.01 to $0.5 \mathrm{~mm} / \mathrm{day}$, but growth is not uniform. Degradation of the metal is superficial, as the depth of attack rarely exceeds $10 \mu \mathrm{m}$, but FFC can destroy the protectiveness of a coating system. On steel, filaments never cross each other and are simply deflected without actually touching, or split into two heads, which then reflect or stop growing at "near-collision.",

Most of the characteristics of FFC are consistent with a differential oxygen concentration cell mechanism, ${ }^{5}$ which requires that the oxygen concentration be much lower in the head than in 
the tail. This is the case if oxygen diffuses primarily through the tail from the original break in the coating, resulting in the separation of anodic and cathodic reaction sites at the front and back of the head, respectively. According to Kaesche, ${ }^{5}$ the steady growth of filiform is attributed to the preservation of a critical amount of electrolyte carried within the head from the point of origin. Note that additional water from the environment is not required for corrosion on steel because conversion of ferrous hydroxide in the head to rust by oxidation can produce water. In this case, water is nearly stationary with respect to the moving head. However, FFC stops when the oxygen supply is severed by sealing off the tail. The separation of anode and cathode explains how directionality is generated and maintained in the head. FFC can exist under a variety of organic or inorganic coatings because the nature and thickness of the coating do not affect the transport properties of oxygen and water through the tail. However, this mechanism fails to explain in detail the rhythmic growth generally observed ("herringbone" patterns) on steel, and there are still uncertainties on the exact location, size, or shape of the cathodic and anodic sites. The process by which disbondment of the coating ahead of the filament occurs on steel is unclear, although different modes have been proposed such as anodic undermining, ${ }^{6}$ cathodic delamination, ${ }^{7}$ and osmotic forces. ${ }^{8}$

Conventional electrochemical techniques have not been successful in providing a descriptive microscopic picture of the processes in the head or in the tail owing to the relatively small size of the filaments and the presence of the coating. Few techniques have the ability to image events under a coating with a size of a few micrometers. The scanning Kelvin probe (SKP), which has a lateral resolution of about $50 \mu \mathrm{m}$, has been used to map the spatial and temporal distribution of Volta potential distributions beneath a thin-film electrolyte or underneath a coating. ${ }^{9-17}$ The delamination front on steel was characterized by a steep change in Volta potential $(500 \mathrm{mV})$. The intact interface had a high potential plateau associated with oxygen reduction, and the delaminated region exhibited lower potentials. SKP maps of FFC on epoxy-coated aluminum alloy 2024-T3 showed a net change potential of $200 \mathrm{mV}$ between the head and the tail. ${ }^{16,17}$

Atomic force microscopy (AFM) and related techniques are powerful tools for the characterization of surfaces with very high spatial resolution. Scanning Kelvin probe force microscopy (SKPFM) was used to produce maps of the Volta potential distribution across surfaces of AA2024-T3 in air. ${ }^{18-21}$ Used in conjunction with topographic measurements, SKPFM, which has a resolution of at least $100 \mathrm{~nm}$, has generated considerable understanding of the role of intermetallic compounds on the corrosion behavior in terms of shape, location, and local practical nobility. Studies of the delamination of ultrathin $(20-100 \mathrm{~nm})$ plasma polymers on specially designed gold samples by SKPFM have shown a loss of spatial resolution of only about $10 \mu \mathrm{m}$ attributable to sample/tip separation and electrical charging of the coating. ${ }^{22}$

The aim of this study was to investigate the mechanism of FFC on coated steel using SKPFM. SKPFM was used to spatially map variations in Volta potential over the surface of corroding plain carbon steel through thin spin-coated epoxy films.

\section{Experimental}

Carbon steel coupons $(1 \times 1 \mathrm{~cm}, 0.3 \mathrm{~cm}$ thick) were cut from a 1045 carbon steel rod. Samples were cold-mounted in epoxy resin, mechanically ground with successively finer $\mathrm{SiC}$ paper through 1200 grit, and finally polished to $1 \mu \mathrm{m}$ diamond paste finishing. A nonaqueous lubricant slurry (Blue Lube by Struers) was used during the grinding and polishing procedures. 
Samples were cleaned ultra-sonically with ethyl alcohol and dried in air $16 \mathrm{~h}$ before use.

Clear epoxy formulations were prepared by mixing commercial epoxy resin (EPON 1001-X-75 by Shell) with a cross-linking agent (EPI-CURE 3115-X-70) in a 2:1 ratio. The solvent methyl ethyl ketone (MEK) was added to the mixture to adjust the viscosity and consequently the thickness of the coating. Thin transparent coatings (150-1000 nm thick) were deposited on the bare sample using a spin-coater at rotating speeds up to $6000 \mathrm{rpm}$. The point of impact of the drop on the sample was intentionally off-center, resulting in a partial coverage of the surface of the sample, while the rest of the sample remained uncovered. This deposition procedure allowed for the measurement of the coating thickness and comparison of the Volta potential of the bare sample to the coated steel on the same sample.

Line-by-line mapping of the topography and Volta potential (by SKPFM) was performed using either a Nanoscope IIIa Multimode atomic force microscope or a Dimension 3100 (both commercial microscopes from Digital Instruments). The maximum operational range of the scanner was $100 \times 100 \mu \mathrm{m}$. SKPFM mapping was performed at a constant lift height of $100 \mathrm{~nm}$. Other details of the SKPFM technique have been described elsewhere. ${ }^{18-21}$ SKPFM measurements were performed using conductive Pt/Ir-coated silicon tips. Unless otherwise noted, Volta potentials are reported with respect to the Volta potential measured in the same atmospheric environment on a pure $\mathrm{Ni}$ sample, which served as a calibration standard. The $\mathrm{Ni}$ sample used as a reference was freshly polished to 1200 grit and then immersed for $30 \mathrm{~min}$ in water prior to each calibration.

Calibration of SKPFM was performed using six pure (>99.95\%) metals covering a large range of the galvanic series: $\mathrm{Mg}, \mathrm{Zn}, \mathrm{Al}, \mathrm{Fe}, \mathrm{Cr}$, and $\mathrm{Ni}$. The open circuit potential (OCP) of the samples was measured in deaerated water after $30 \mathrm{~min} v s$. a reference saturated calomel electrode. Samples were then air-dried, and the Volta potential was immediately measured in air by SKPFM. A $150 \mathrm{~nm}$ thick epoxy coating was deposited on the surface by spin-coating. The coating was allowed to cure for 7 days in air and retested. Reported Volta potentials consist of an average of five individual measurements at randomly selected $1 \times 1 \mu \mathrm{m}$ regions on the surface. Again, the values are referenced to the Volta potential of pure Ni, which serves as an internal standard. The error associated with SKPFM measurements was estimated at $25 \mathrm{mV}$

The coated sample was extracted from its mounting resin to expose all edges to the environment. FFC was initiated by exposing the coated sample to fumes of concentrated $\mathrm{HCl}$ for $10 \mathrm{~min}$. Upon exposure to acid fumes, rust formed on the bare top surface, edges, and bottom of the specimen. The coated top surface did not reveal any indication of corrosion at this point. The sample was then kept in a humidity chamber, where a constant relative humidity (RH) of $93 \%$ was maintained by the presence of a solution containing an aqueous solution saturated with sodium sulfite. After an incubation period of 2 to 3 days, blisters and filaments formed on the edge of the coating. The samples were periodically transferred to the AFM microscope for analysis. The Multimode AFM microscope was equipped with a cylindrical plastic hood, which allowed purging of the Multimode environment at or slightly above atmospheric pressures with gases such as air or humid air while scanning. Humid air was generated by flowing dry air through a series of bubblers filled with a solution containing the saturated sodium sulfite solution. A relative humidity (RH) of $93 \%$ was measured with a hygrometer sensor placed in the hood. During transfer of the samples from the humidity chamber to the AFM microscope, they were first examined with an optical microscope to assess the extent of filament progress. This low RH exposure sometimes affected the subsequent growth, and the samples were exposed to the high $\mathrm{RH}$ atmosphere of the AFM hood for at least $24 \mathrm{~h}$ prior to AFM analysis to reinitiate the 
sites.

The size of some filaments prevented accurate topographic characterization by AFM. Some filament tails were characterized by a Dektak ${ }^{3} \mathrm{ST}$ stylus profiler from Veeco. The vertical range of this instrument is $100 \mu \mathrm{m}$ with a vertical resolution of $1 \mathrm{~nm}$. It was calibrated with a 1 $\mu \mathrm{m}$ calibration standard. The applied load was $20 \mathrm{mg}$, and high resolution scans consisting of 8000 data points were performed. When the same area of a filament needed to be documented several times, fiducial marks in the vicinity of the tail were used to ensure that the same location was traced.

\section{Results and Discussion}

Calibration of SKPFM measurement on an epoxy-coated sample.- It has been shown by Stratmann and coworkers $^{23,24}$ that the corrosion potential $E_{\text {corr }}$ of a bare metal covered with a layer of electrolyte (measured with a reference electrode placed in the thin electrolyte) is related linearly to the Volta potential difference between the reference probe positioned just above the electrolyte and the electrolyte according to the following equation

$$
E_{\text {corr }}=\frac{W_{\mathrm{e}}^{\mathrm{ref}}}{F}-\chi_{\mathrm{gas}}^{\mathrm{sol}}+E_{1 / 2}+\Delta \Psi_{\mathrm{sol}}^{\mathrm{ref}}
$$

where $W_{\mathrm{e}}^{\mathrm{ref}}$ is the electronic work function of the reference probe material, $F$ is the Faraday constant, $\chi_{\mathrm{g} \text { as }}^{\mathrm{sol}}$ is the dipole potential of the solution/gas interface, $E_{1 / 2}$ is the half-cell potential of the reference electrode, and $\Delta \Psi$ sol is the measured Volta potential difference between the reference probe and the solution/gas interface.

For a polymer-coated metal surface, a similar equation has been derived ${ }^{21}$

$$
E_{\text {corr }}=\frac{W_{\mathrm{e}}^{\mathrm{ref}}}{F}-\chi^{\mathrm{pol}}+E_{1 / 2}+\Delta \Psi_{\mathrm{pol}}^{\mathrm{ref}}
$$

where $\chi^{\mathrm{pol}}$ is the dipole potential of the polymer, and $\Delta \Psi_{\mathrm{pol}}^{\mathrm{ref}}$ is the measured Volta potential difference between the reference probe and the polymer/gas interface. If a layer of electrolyte layer is present on the metal substrate underneath the polymer as a result of delamination, an additional term should be added to the right side of Eq. 2, the Donnan potential (i.e., Galvani potential difference) between the polymer and the electrolyte. The Donnan potential can be ignored for polymers with a low density of fixed charges (a good assumption for epoxy), or if the electrolyte layer under a delaminated film is sufficiently concentrated. Note that the calibration constant between the corrosion potential and the Volta potential $\left(W_{\mathrm{e}}^{\mathrm{ref}} / F-\chi^{\mathrm{pol}}+E_{1 / 2}\right)$ contains the work function of the probe, which may depend on the surface condition of the reference probe material in a given environment.

Figure 1 shows a plot of Volta potential vs. OCP for the six pure metals, each with three different surface preparations: bare after immersion in deaerated water, epoxy-coated after 1 week storage in air, and epoxy-coated after 2 months in air. Except for Zn, the Volta potentials of metals show a linear dependency on OCP with a slope close to unity, which has been reported previously for Volta potentials measured by SKPFM. ${ }^{19}$ The reason for the singularity of $\mathrm{Zn}$ is unknown. The Volta potential difference for metals covered with a $150 \mathrm{~nm}$ film of epoxy was about $50 \mathrm{mV}$ higher than for the bare metal. According to Eq. 2, this small change can be explained by the dipole potential of epoxy. Dipole potentials have been reported to be on the order of $60 \mathrm{mV}^{25}$ After a storage period of 2 months in lab air, the Volta potentials of the most 
active metals $(\mathrm{Mg}, \mathrm{Zn}, \mathrm{Al})$ rose by $200 \mathrm{mV}$, while potentials of the noble metals remained unchanged. All coated samples were stored and measured in the same conditions; thus, the calibration constant remained identical for all samples, and any increase in Volta potential is caused by an increase in the corrosion potential of the metal. Optical inspection of the surface did not reveal any sign of corrosion underneath the coating, but some microscopic modification of the surface may have taken place.

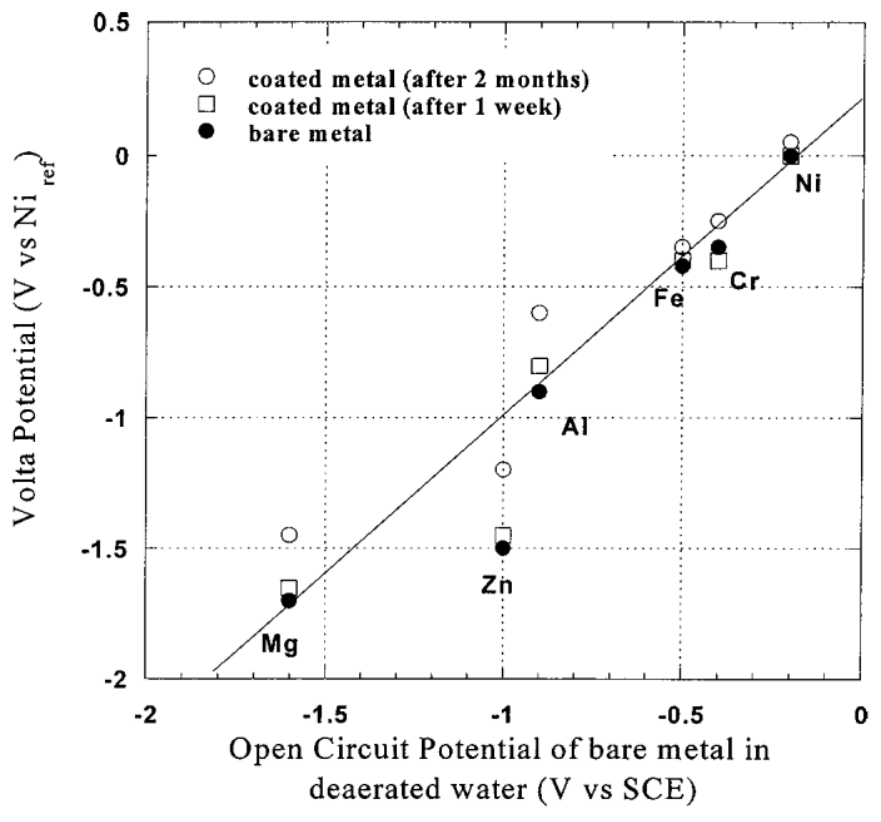

Figure 1. Calibration of SKPFM. Volta potential measured in air immediately after water immersion.

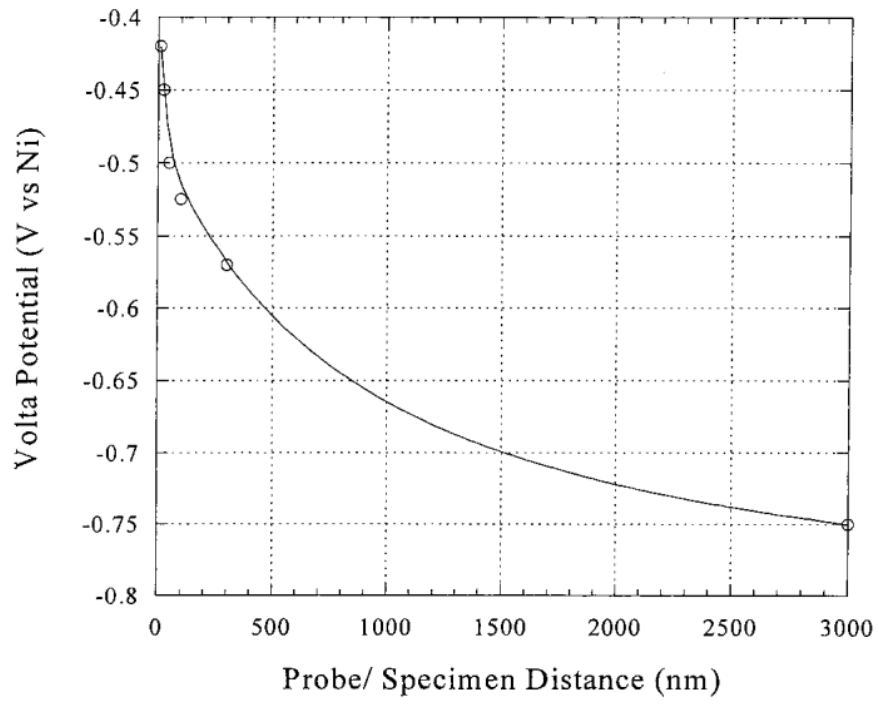

Figure 2. Volta potential measurement of an inclusion of radius $10 \mu \mathrm{m}$ and Volta potential $\Psi_{1}=-0.4 \mathrm{~V}$ surrounded by a large matrix of Volta potential $\Psi_{2}=-0.75 \mathrm{~V}$. 
The calibration curve is linear in a large range of potentials and justifies the use of SKPFM for detection of cathodic and anodic regions in filaments through a thin polymer coating.

The lateral resolution of SKPFM is highly dependent on the distance between the tip and the respective surface features being mea- sured. Figure 2 shows an example of the influence of tip/sample separation on measured Volta potential. Measurements were performed on an uncoated sample of AA 2024-T3 at a controlled vertical distance from the center of a $10 \mu \mathrm{m} \mathrm{Al-}$ $\mathrm{Cu}-\mathrm{Fe}-\mathrm{Mn}$ inclusion. At a distance of $100 \mathrm{~nm}$, which is typically used in SKPFM, ${ }^{26}$ the measured Volta potential directly above the inclusion is $-0.4 \mathrm{~V}$. As the distance between the tip and the inclusion increases, the measured potential drops because of the contribution of the surrounding matrix, which has a lower potential. For large separations $(>3 \mu \mathrm{m})$, the measured potential approaches the potential of the matrix, $-0.75 \mathrm{~V}$. Therefore, if good lateral resolution is desired, the tip/substrate distance should be minimized.
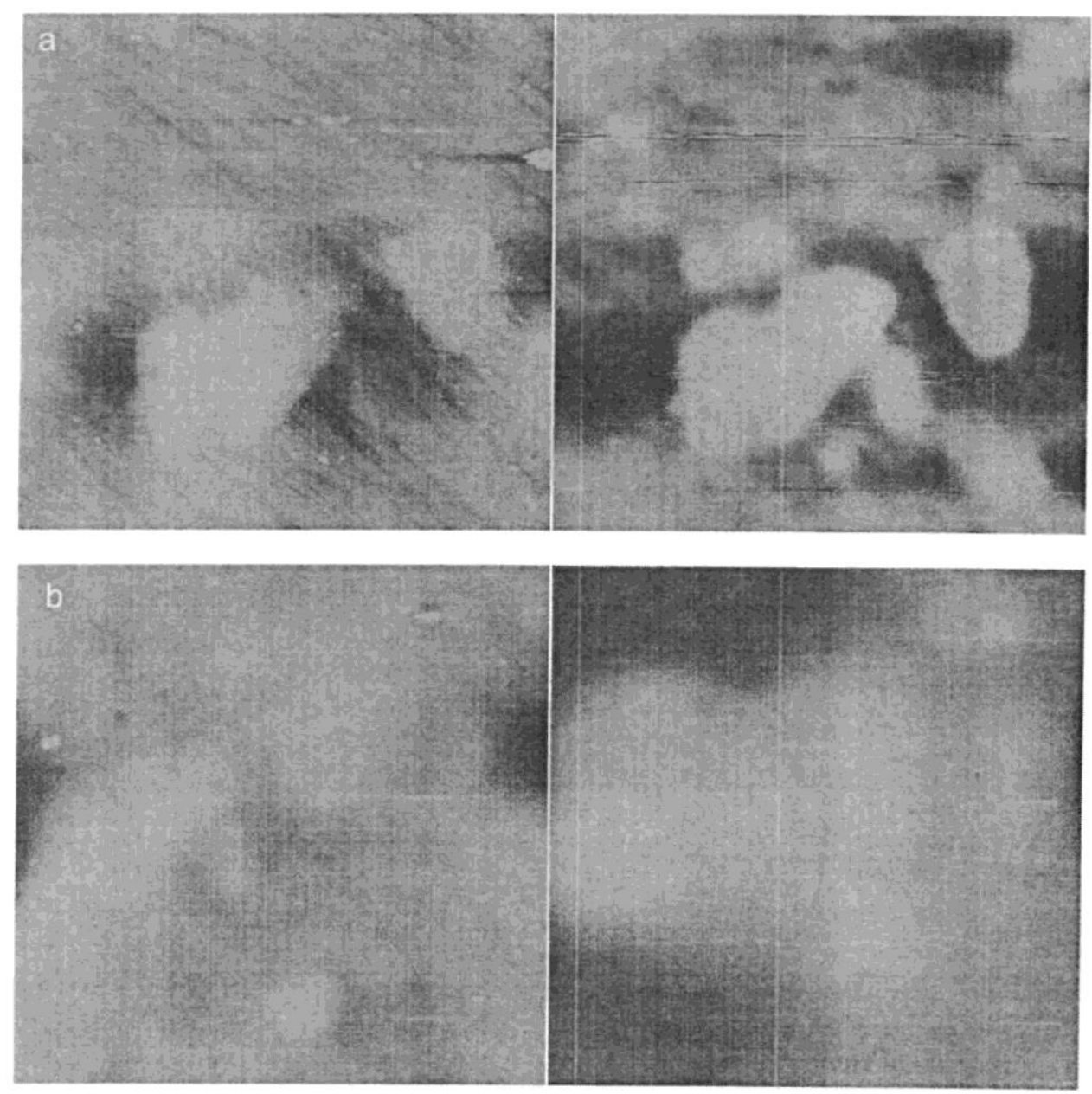

Figure 3. SKPFM of AA2024-T3: (a) as-polished and (b) the same area coated with $150 \mathrm{~nm}$ epoxy film. Area of scan is $40 \times 40 \mu \mathrm{m}$. Note that there is a slight offset in the location of the scan on the coated sample relative to the uncoated sample. The topographic images on left have a full scale range of $1 \mu \mathrm{m}$, and the potential maps on right have a full scale range of $1 \mathrm{~V}$. 


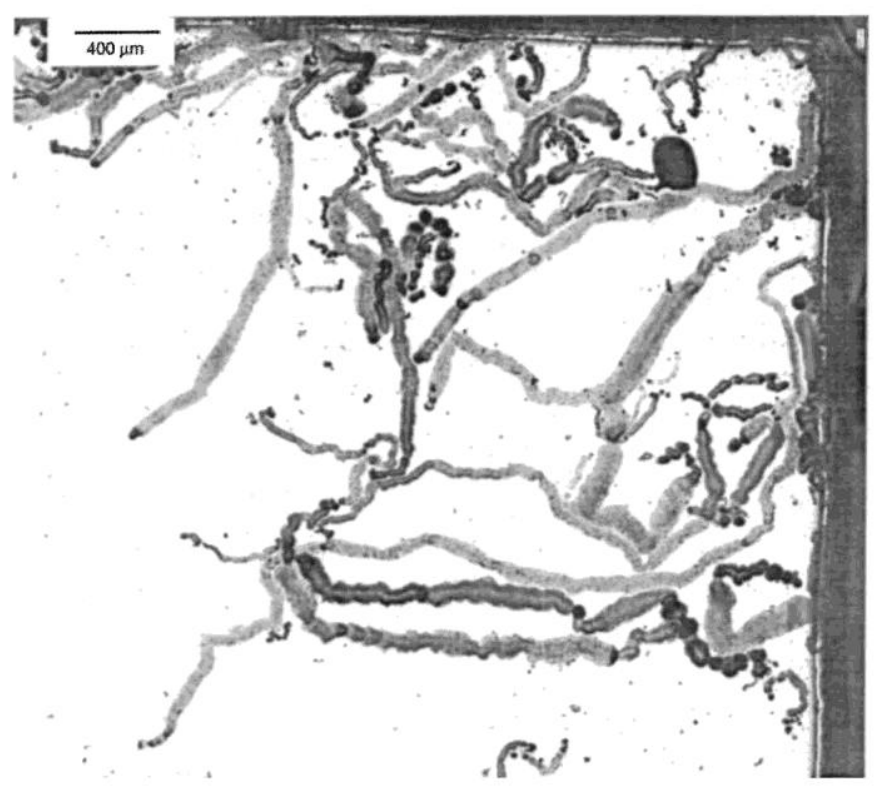

Figure 4. Optical image of FFC on carbon steel under $300 \mathrm{~nm}$ epoxy film. Sample was stored 6 weeks at $24^{\circ} \mathrm{C}$ in $\mathrm{RH}=93 \%$.

For reasonable lateral resolution through coated samples, thin coatings were engineered for this study. The lateral resolution through thin epoxy films was evaluated on an AA2024-T3 substrate. Figure 3a shows the topography and Volta potential map of an area of an as-polished AA2024-T3 sample measured at a distance of $250 \mathrm{~nm}$ above the surface. The few raised regions visible in the topographic map (left image) are associated with inclusions protruding from the surface because of a lower rate of polishing. The numerous bright regions in the Volta potential map (right image) are associated with intermetallic particles. All intermetallic particles exhibit

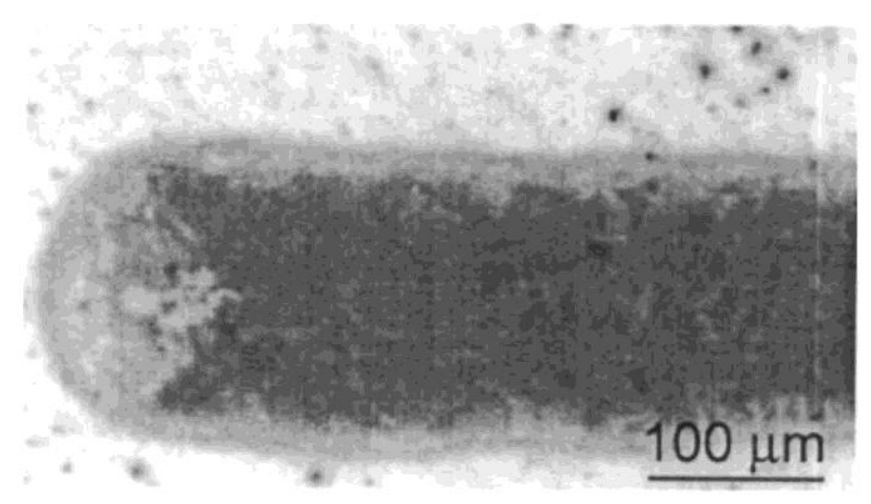

Figure 5. Optical image of active filament. Interface between active head (left) and tail (right) has a Vshape.

a higher Volta potential than the matrix. ${ }^{18,19}$ Figure $3 \mathrm{~b}$ shows SKPFM scans of the same region 
after a $150 \mathrm{~nm}$ epoxy coating was deposited. The tip was located $100 \mathrm{~nm}$ above the surface of the coating (250 nm away from the substrate, which is the same distance used for the uncoated sample in Fig. 3a). The raised particles observed in Fig. 3a are still visible in the topographic map of Fig. 3b, indicating that the thin epoxy film conforms to the surface. The presence of epoxy clearly degrades the lateral resolution in the potential map. Previously sharp features increased in size by 3-5 $\mu \mathrm{m}$ in every direction under the coating. Despite some resolution loss through epoxy films, SKPFM characterizes the potential distribution across a surface. Therefore, although Volta potential differences could be measured through coatings a few micrometers thick, the use of coatings in the range of hundreds of nm was preferred to profit from the intrinsic high resolution of SKPFM.

FFC under $300 \mathrm{~nm}$ thick epoxy films. - After exposure to humid air (93\% RH) for 6 weeks, a network of filaments decorated the surface of the coated steel sample. FFC started at all edges and at defects in the coating where bare metal was exposed to the initiating salt, Fig. 4. Filaments had a worm-like appearance, were 100- to $200 \mu \mathrm{m}$ wide, and grew relatively straight for long distances (many $\mathrm{cm}$ in some cases). However, most of them changed direction at least once. They grew at an average velocity of $7 \times 10^{-3} \mu \mathrm{m} / \mathrm{s}(0.6 \mathrm{~mm} /$ day $)$. Tracks never crossed each other, and they changed direction or died when approaching another track. Surface crowding eventually resulted in the majority of filaments spiraling to their deaths. In two instances, a smaller filament was seen branching out of a dead track. In the active state, the filaments were composed of two optically distinguishable parts: a brown tail filled with corrosion products and a greenish-blue head. The boundary between head and tail was easily identified by color contrast and a characteristic V-shape, Fig. 5. In the inactive state after a filament stopped growing, the heads turned brown and contained a raised black dome of corrosion products

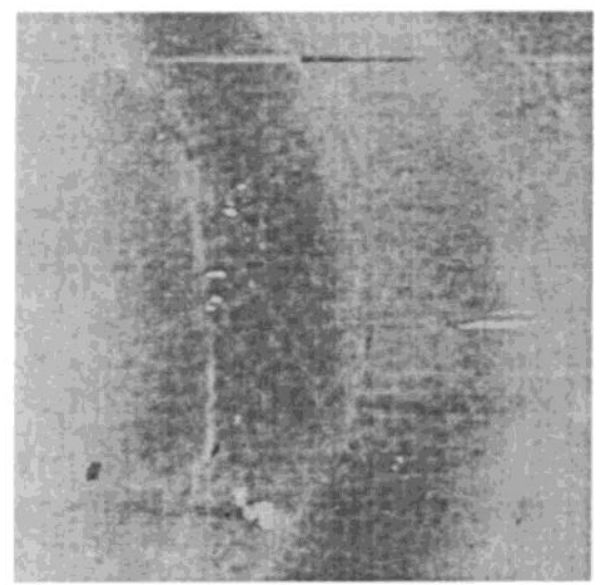

a)

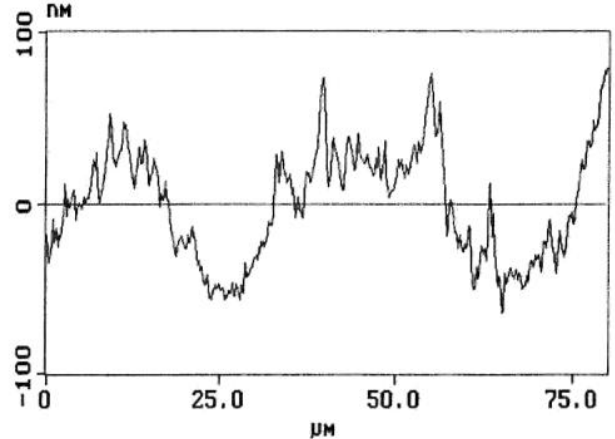

b)

Figure 6. Top surface of tail with coating present on surface. (a) AFM topographic image of $80 \times 80 \mu \mathrm{m}$ area. Full scale range is $1 \mu \mathrm{m}$. (b) Line scan along top of tail. 


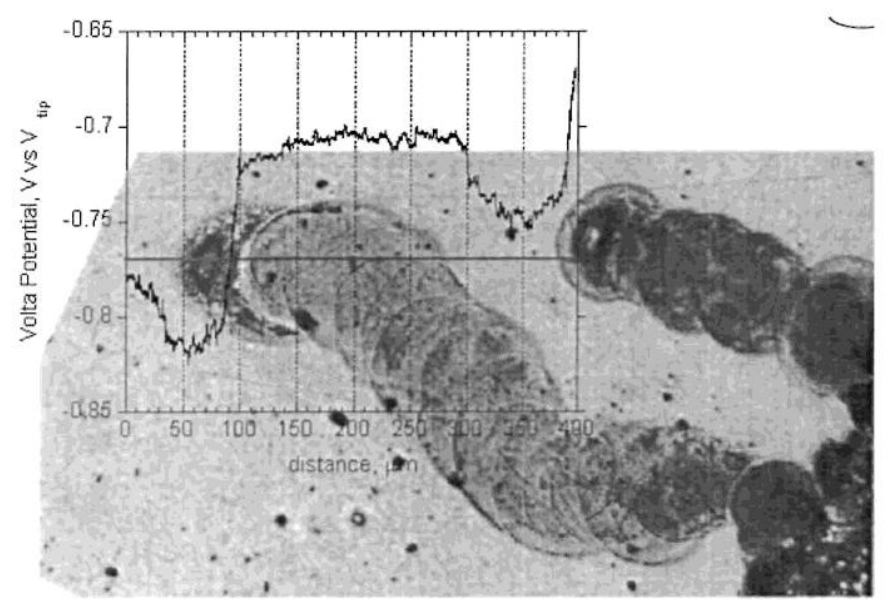

Figure 7. SKPFM line scan across the surface of carbon steel substrate covered by $300 \mathrm{~nm}$ epoxy coating. Ten successive and overlapping $50 \mu \mathrm{m}$ Volta potential maps were stitched together to produce the profile. The underlying image is an optical micrograph. The location of the scanned line on the image is only approximate.

An attempt was made to correlate the height of the solid products in the tail and the depth of attack to the nature of the corrosion products. Measurements of tail height were performed on active filaments while the coating was still in place with a stylus profiler immediately removal from the humidity chamber. The depth of attack was measured with the same apparatus after removing the coating in MEK and selectively dissolving the corrosion products present in the track with a mixture of $0.1 \mathrm{M}$ boric $+5 \times 10^{-4} \mathrm{M}$ acetic acid. Energy-dispersive spectroscopy analysis revealed that tails contained $\mathrm{Fe}$ and $\mathrm{O}$, but no chloride (initiating anion) and very little sulfite salts (used to maintain constant humidity in chamber). However, $\mathrm{Cl}$ was found in the black corrosion products in the head. The average height of tails in the active state was $2 \mu \mathrm{m}$. The depth of attack into the metal was very shallow $(0.3 \mu \mathrm{m})$, and black products in the head of a dead filament were about $6 \mu \mathrm{m}$ in height. Height and depth data on several filaments were converted to volume change relative to the corroded metal. The average volume change was 7 times for an active tail and 20 times for a dry head. Based on volume change and color, one can conclude that for a growing filament the black product formed in the head is probably $\mathrm{FeCl}_{3} \cdot 6 \mathrm{H}_{2} \mathrm{O}$, and the tail is most probably $\mathrm{Fe}(\mathrm{OH})_{3}$.

Investigation of the tail and head was conducted with the AFM microscope. Complete transverse scans of tails were possible in only few instances, when the height of the tail did not exceed the vertical limit of the microscope. Imaging of the head proved to be even more challenging because of the presence of solution underneath the thin epoxy film. The contact-mode landing or tapping-mode close approach was prevented by oscillations of the delaminated coating. This phenomenon was worst in the region toward the back of the head where the liquid thickness is the greatest. AFM topographic analysis of the top surface of the tail (which is solid and can easily be imaged) revealed a series of repeating annular ridges with a periodicity of $25-30 \mu \mathrm{m}$ and about $100 \mathrm{~nm}$ high (5\% of the total tail height), Fig. 6 . This pattern has been referred to in the literature as a herringbone pattern. It can be explained by a cyclic growth pattern of active corrosion until the head reaches a critical size, slowdown, and reactivation. The critical size of the head may be dictated by the availability of cathodic reactants to support the metal dissolution 
rate (current density). The spacing between successive ridges suggests that the sequence of events takes $1 \mathrm{~h}$.

Figure 7 shows an in situ Volta potential line scan across a filament on the carbon steel substrate. This experiment represents one of a few successful attempts to land on all parts of the head of an active filament. Ten successive and overlapping $50 \mu \mathrm{m}$ SKPFM lines were captured by moving the stage by increments of $40 \mu \mathrm{m}$. The lines were stitched together to produce this profile. This process can result in offsets in potential over long distances, which is likely why the

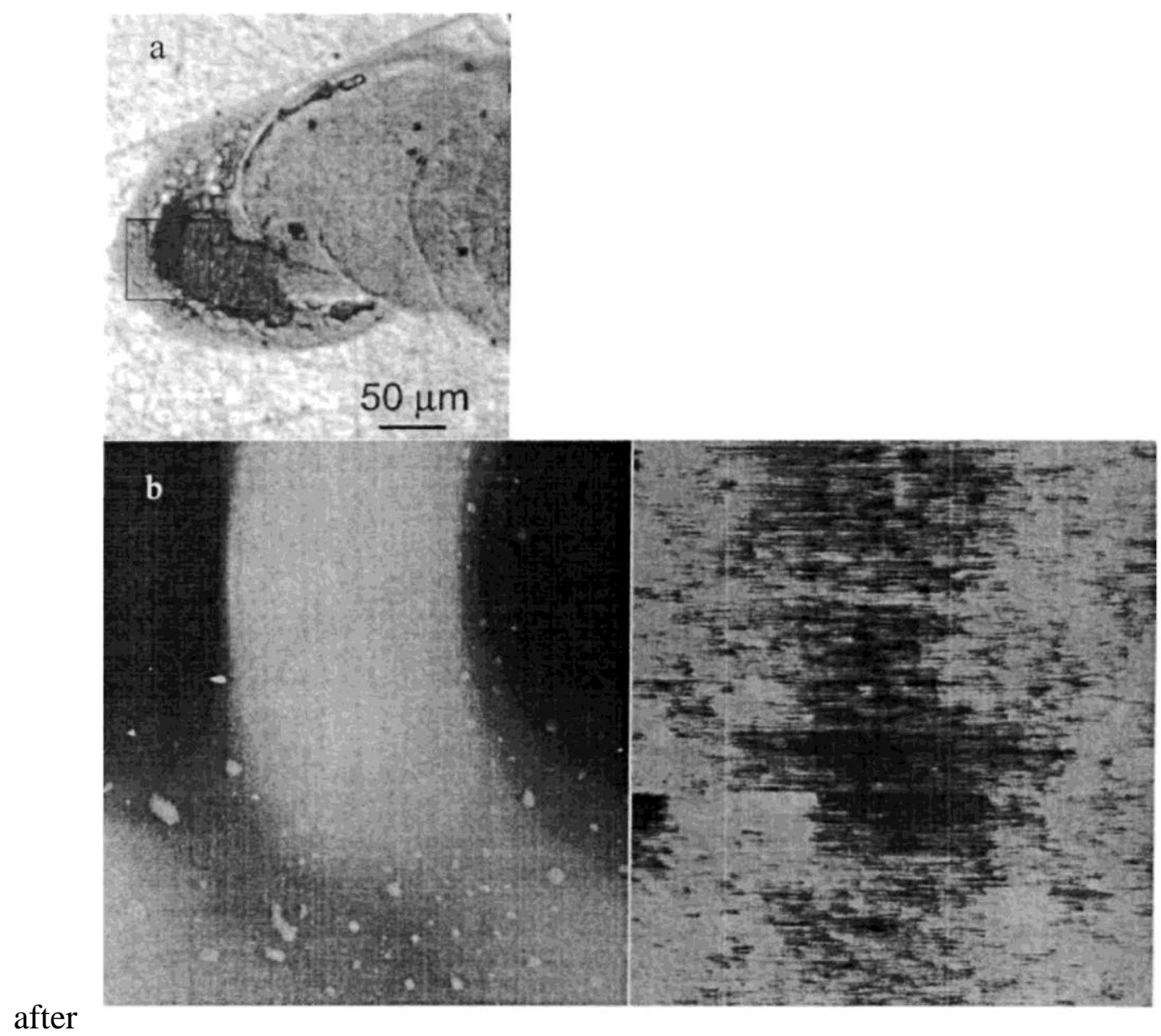

Figure 8. Filament growing under $300 \mathrm{~nm}$ coating in $\mathrm{RH}=93 \%$. (a) Optical image containing box indicating region of SKPFM mapping. Image was taken in air immediately after AFM in situ imaging. Filament dried out during optical microscopy. (b) SKPFM image of interior of active head topography (left, full scale range of $1 \mu \mathrm{m}$ ) and Volta potential (right, full scale range of $0.1 \mathrm{~V}$ ) of $60 \times 60 \mu \mathrm{m}$ area. 

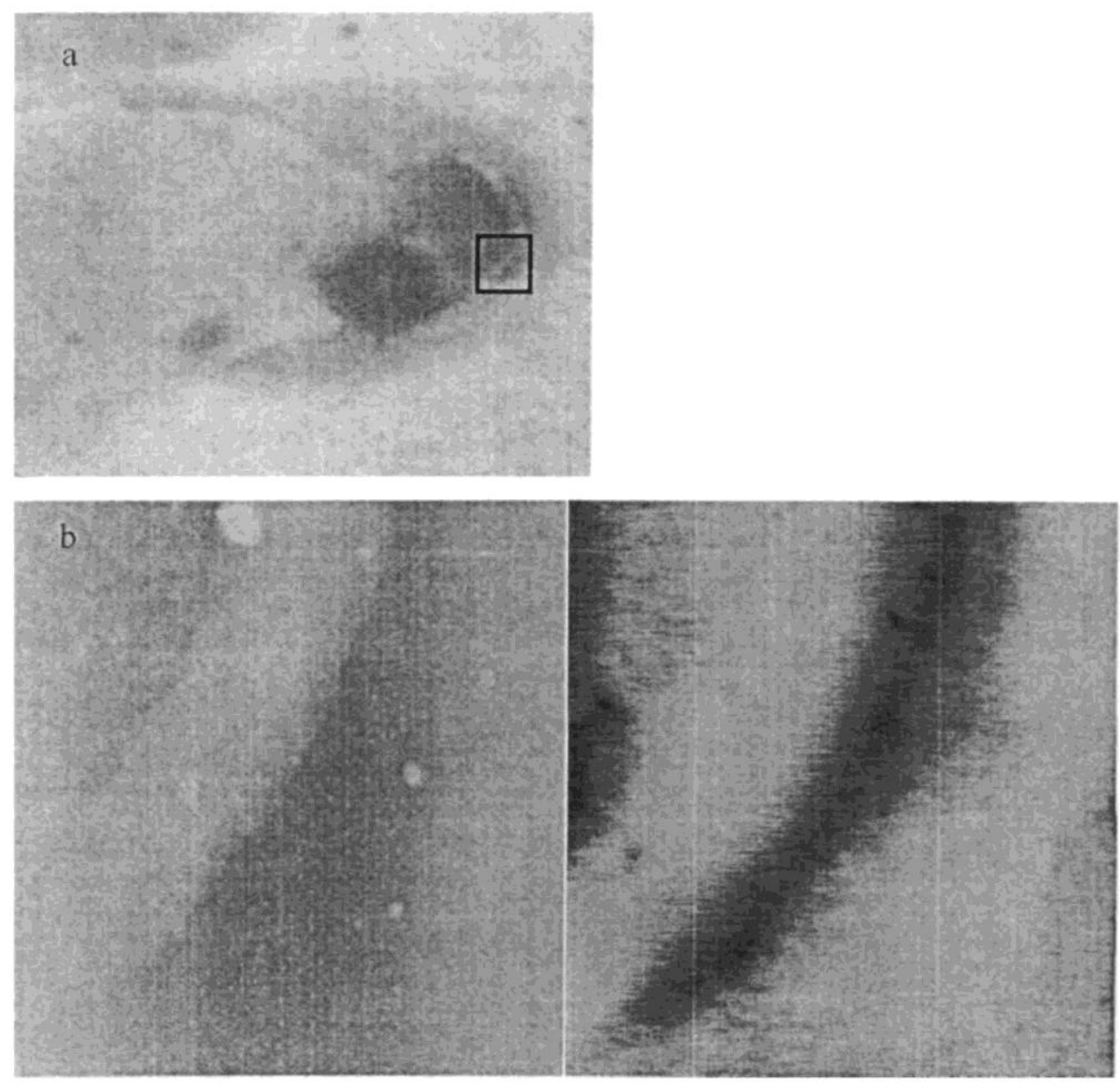

Figure 9. Filament growing under $300 \mathrm{~nm}$ coating in $\mathrm{RH}=93 \%$. (a) Optical image containing box indicating region of SKPFM mapping. Image was taken in air immediately after AFM in situ imaging. Filament dried out during optical microscopy. (b) SKPFM image of front of active head topography (left, full scale range of $1 \mu \mathrm{m}$ ) and Volta potential (right, full scale range of $0.2 \mathrm{~V}$ ) of $40 \times 40 \mu \mathrm{m}$ area.

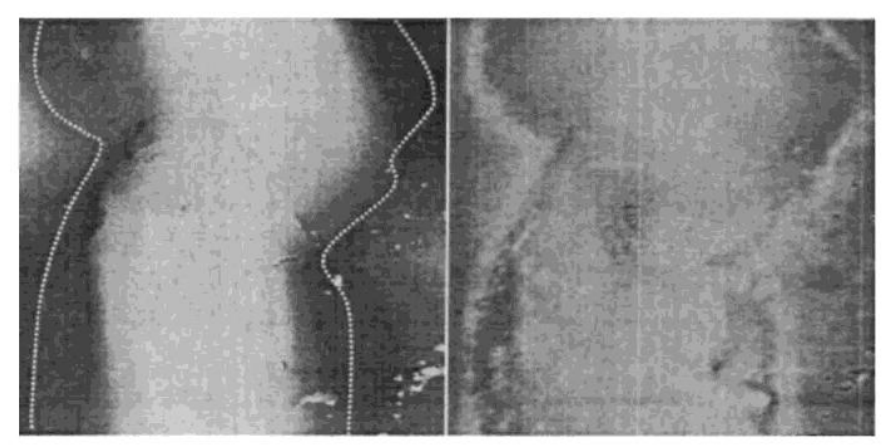

Figure 10. SKPFM of tail after epoxy removal. Left: topography (full scale range of $1 \mu \mathrm{m}$ ). Right: potential (full scale range of $0.5 \mathrm{~V}$ ). Area of scan is $80 \times 80 \mu \mathrm{m}$. Dashed lines in topography map correspond to bright lines in potential map associated with voids. Features in the topographic image exceed the vertical limits of the AFM microscope. 
potential between the two filaments is different than the potential in front of the filament on the left. The corrosion products in the tail far behind the head cause a high Volta potential in this region. It is unlikely that the extended tail is an active cathodic site where oxygen is reduced because of the lack of electrolyte there. The blue-colored region of the head, where active dissolution takes place, has a low potential. However, the size and the location of active cathodes and anodes are unclear, and high-resolution images are needed.

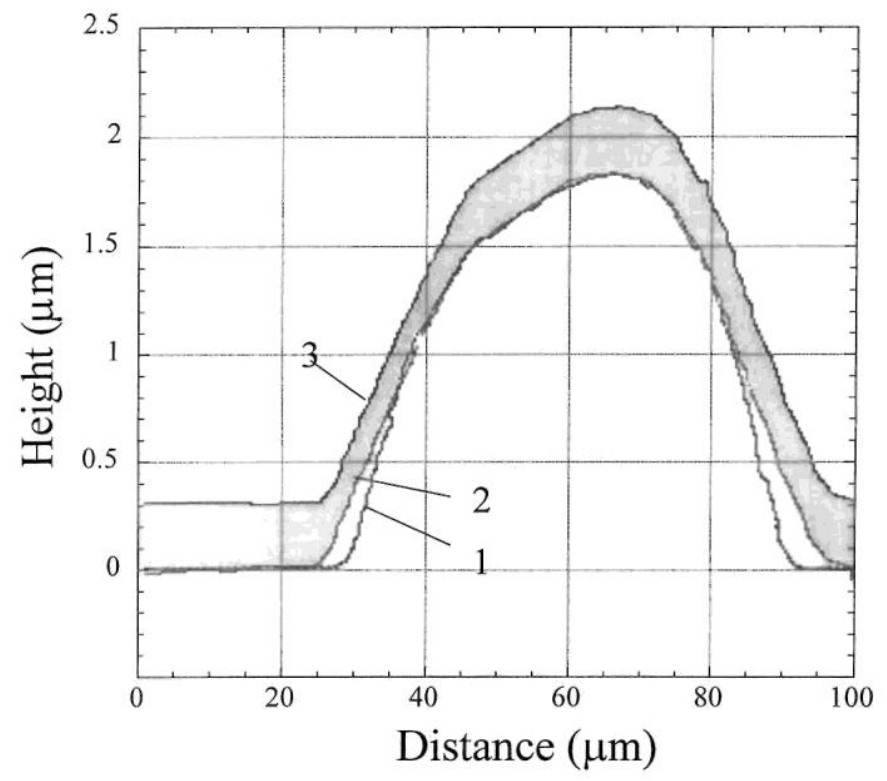

Figure 11. Transverse profile of tail measured (1) with coating removed, (2) prior to removal of the coating, and (3) with coating in place and displaced upward by a distance equal to the coating thickness, $300 \mathrm{~nm}$.

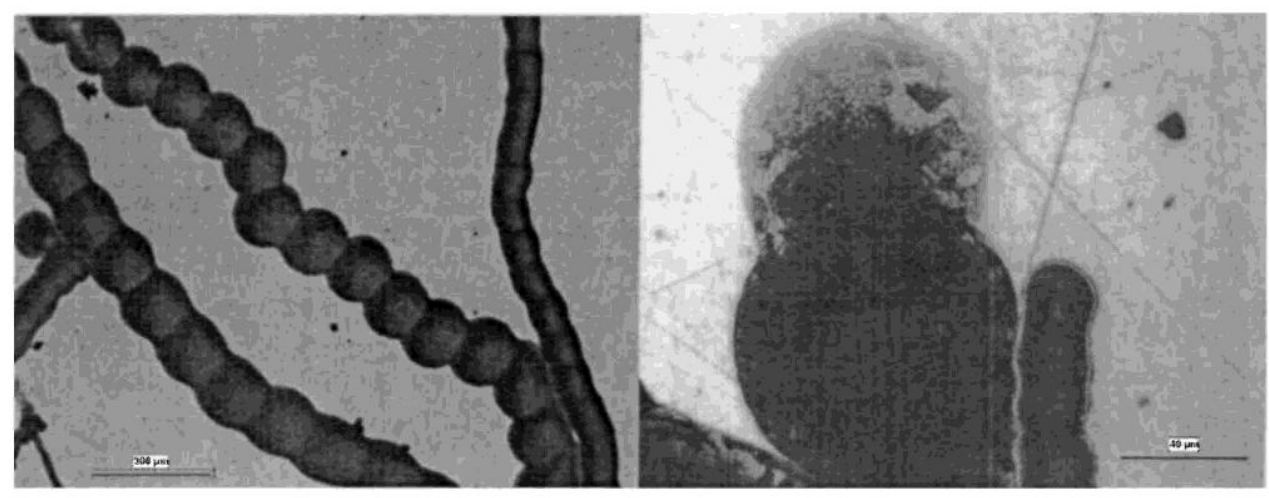

Figure 12. Optical images of FFC on carbon steel under $150 \mathrm{~nm}$ epoxy film. Sample was stored 8 weeks at $24^{\circ} \mathrm{C}$ at $\mathrm{RH}=93 \%$. 
High-magnification SKPFM images of selected regions of the tail and the head were captured to study in more detail the location and size of cathodic and anodic regions. SKPFM mapping of the interior of an active head is shown in Fig. 8. The head contains both anodic and cathodic regions. However, the contrast is poor, and the magnitude of the difference is small (50 $\mathrm{mV}$ ). The raised region in the topographic image corresponds to the dark region in the top optical picture. Energy-dispersive X-ray analysis analysis indicated the presence of chloride in this region of other filaments. Therefore, the raised region is associated with a chloride-containing solution. The lower potential of this region indicates that it is an anode.

The front edges of filament heads exhibit finer detail, as shown in Fig. 9. Several anodic (dark) and cathodic (bright) regions can be observed in the potential map. Active cathodic areas are present on the periphery of the head, possibly resulting in cathodic disbondment of the epoxy coating by alkali attack. This alternating cathodic and anodic region was typically found on the edge of the head near the front of the tail and usually did not completely encircle the active filament head.

The epoxy was removed by soaking in MEK, and the tails were reanalyzed in detail. In Fig. 10, the topographic image clearly shows segments of solid corrosion products in the tail. The highest regions are located in the middle of each segment. The solids are characterized by a high Volta potential difference of $300 \mathrm{mV}$ with respect to the uncorroded substrate. This potential difference is higher than for the coated sample in $93 \% \mathrm{RH}$. This can be explained by the difference in water content in the tail under the coating in a high humidity atmosphere and in the dry products in air. The most striking features of the potential map are two continuous $5 \mu \mathrm{m}$ wide bands of high potential measured $10-20 \mu \mathrm{m}$ from the corrosion products in the tail. The locations of these potential bands are traced out in the topographic map. The region between the tail and the high potential band appears to be free of corrosion products, and its Volta potential is that of uncorroded steel. The reason for the high potential in the band is unclear at this point, but it is believed that the band marks the location of the delamination front. To verify this assumption, transverse profiles of a tail coated with epoxy and after coating removal were performed with a stylus profiler. The vertical resolution of the instrument is $1 \mathrm{~nm}$, and, because scans as large as $5 \mathrm{~mm}$ can be acquired, one or more tails can be documented at once.

Figure 11 shows transverse scans of a tail measured with coating removed (curve 1) and prior to removal of the coating (curve 2). Curve 3 is a scan with the coating in place but displaced upward by a distance equal to the coating thickness. Fiducial marks in the vicinity of the tail were used to ensure that the same location was traced both times. The area shaded in gray therefore represents the cross section of the coating, assuming that the coating thickness remains uniform at each point along the line. Note that the $y$ axis is greatly expanded relative to the $x$ axis. By this analysis, curve 2 represents the bottom side of the coating. Curves 1 and 2 (the top of the corrosion product and the bottom of the coating) overlap along the top half of the tail but not along the edges. If curve 2 is a true representation of the bottom side of the coating, then there are apparent voids at the edges of the tail beneath the coating. The void cross section is approximately $10 \times 0.2 \mu \mathrm{m}$, which is consistent with the SKPFM observations of Fig. 10. These voids along the edge of the dry corrosion products could be caused by cathodic disbondment aided by mechanical prying of the epoxy film by the voluminous product. Such voids could be critical components in the filament growth process. They probably provide fast path channels for $\mathrm{O}_{2}$ diffusion relative to transport through the solid tail and could explain the observed $\mathrm{V}$-shape of the interface between the solution in the active head and the precipitated products. The bending forward of the $\mathrm{V}$-shape near the edges implies that the tail must be more permeable to oxygen 
there. ${ }^{1}$ The presence of these voids also provides an explanation for the puzzling observation that filaments deflect off tails without actually touching and never collide. When an active head approaches within $20 \mu \mathrm{m}$ of the body of a tail, it is exposed to a new source of oxygen contained in the void, and it changes direction. The new direction is the vectorial sum of the two combined oxygen fluxes.

FFC under $150 \mathrm{~nm}$ thick films. - FFC of 1045 steel under a thinner $150 \mathrm{~nm}$ epoxy coating was investigated using the same experimental procedures and methodology. The incubation time for the formation of filaments of 2-4 days was the same. However, the most striking difference was the morphology of attack. Figure 12 shows images of FFC under a $150 \mathrm{~nm}$ thick epoxy coating after 8 weeks at $93 \% \mathrm{RH}$. The filaments resembled strings of beads. The average diameter of a bead was about $150 \mu \mathrm{m}$. The $\mathrm{V}$-shaped feature between head and tail regions was never seen under the thin coating. The profile of the top surface along the growth direction is plotted in Fig. 13. The periodicity of the beads along the dry tail was $150 \mu \mathrm{m}$, which is equivalent to $10 \mathrm{~h}$. The variation in amplitude along the top surface was about $2 \mu \mathrm{m}$, but the average total height (substrate to crest) measured on a transverse profile was 4-6 $\mu \mathrm{m}$. Relative to FFC under the $300 \mathrm{~nm}$ coating, the attack into the steel was about twice as deep $(0.7 \mu \mathrm{m})$, and the average growth rate was half as fast $\left(4 \times 10^{-3} \mu \mathrm{m} / \mathrm{s}\right)$. As a result, the total rate of iron dissolution in moles/second was approximately equal for the two film thicknesses. A SKPFM image of the head of a narrow string of beads (width $<100 \mu \mathrm{m}$ ) is presented in Fig. 14. The raised region at the bottom of the left topographic image is the leading bead of the string. It is associated with the brightest potential contrast in the right image. A Volta potential difference contrast was never observed in the heads of filaments under the $150 \mathrm{~nm}$ coating. The fact that neither anodic nor cathodic regions were identified in the potential map could be the result of a smaller IR drop between anodes and cathodes relative to the case of the thicker film. The IR drop would be controlled by the conductivity of the electrolyte in the head and the presence of resistive features such as solid or gel corrosion products. In contrast to filament heads under the $300 \mathrm{~nm}$ coating, which might contain such resistive features causing IR drops, the filament heads under the $150 \mathrm{~nm}$ coating appear to be more uniform with no resistive features. However, a high potential associated with cathodic activity was observed ahead of the leading bead and on the periphery of the head under the $150 \mathrm{~nm}$ coating. There was no topographic contrast in these regions. This cathodic region is further support of a cathodic disbondment mechanism.

The radial growth of the head in the form of beads and the cathodic activity in front of the head suggest that $\mathrm{O}_{2}$ mass transport through the coating is more important relative to transport through the tail for the thin coating. As was the case for thicker coatings, voids resulting from coating delamination beyond the dry tail were also observed. Mass transport in FFC.-The physical characteristics of the filaments are summarized in Table 1. The iron dissolution rate $(\mathrm{mol} / \mathrm{s})$ was calculated from the propagation rate, filament width, and depth of attack into the metal. The anodic current density $\left(\mathrm{A} / \mathrm{cm}^{2}\right)$ was calculated from the dissolution rate and active head area, assuming $n=2$ equiv/mol. As already mentioned, the dissolution rates under 150 and $300 \mathrm{~nm}$ coatings are approximately equal. The diffusion coefficient for $\mathrm{O}_{2}$ in hydrated epoxy was reported to be $1.1 \times 10^{-9} \mathrm{~cm}^{2} / \mathrm{s}$. Theconcentration of oxygen in air is $8.6 \times 10^{-6}$ $\mathrm{mol} / \mathrm{cm}^{3}$. Assuming one-dimensional diffusion of $\mathrm{O}_{2}$ through the coating to the active area of the head, the flux of $\mathrm{O}_{2}$ reaching the head through the epoxy coating can be calculated to be $1.1 \times$ $10^{-13}$ and $2.0 \times 10^{-14} \mathrm{~mol} / \mathrm{s}$ for 150 and $300 \mathrm{~nm}$ coatings, respectively. Converting to current density, the rate of cathodic reaction associated with $\mathrm{O}_{2}$ diffusion is $2.5 \times 10^{-4}$ and $1.2 \times 10^{-4}$ 


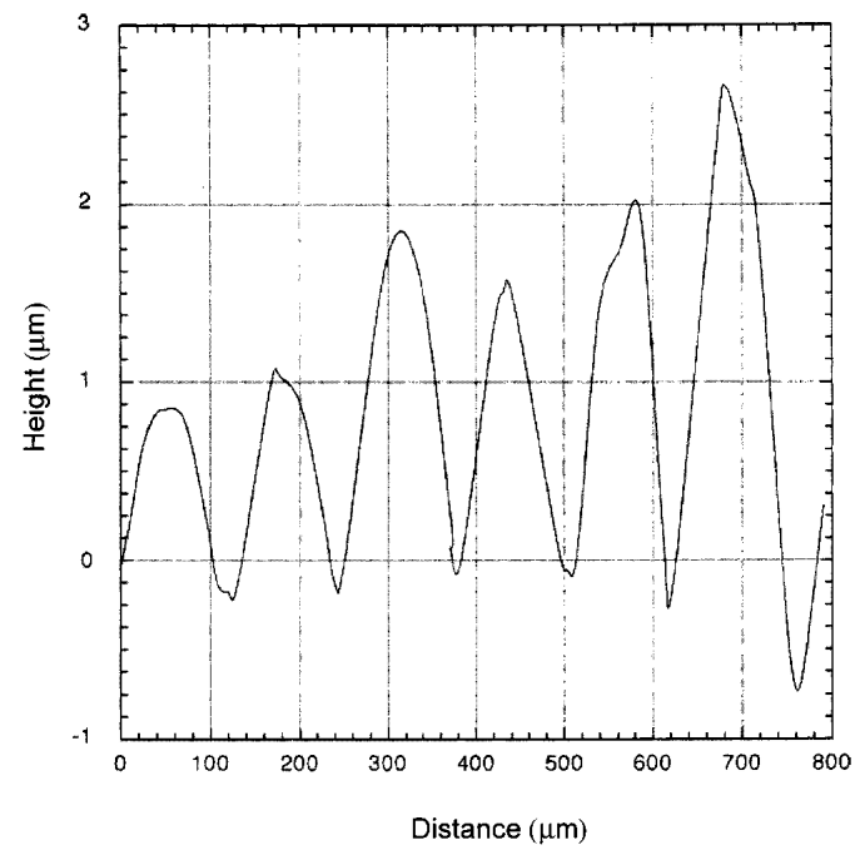

Figure 13. Longitudinal scan of top surface of tail under $150 \mathrm{~nm}$ epoxy coating.
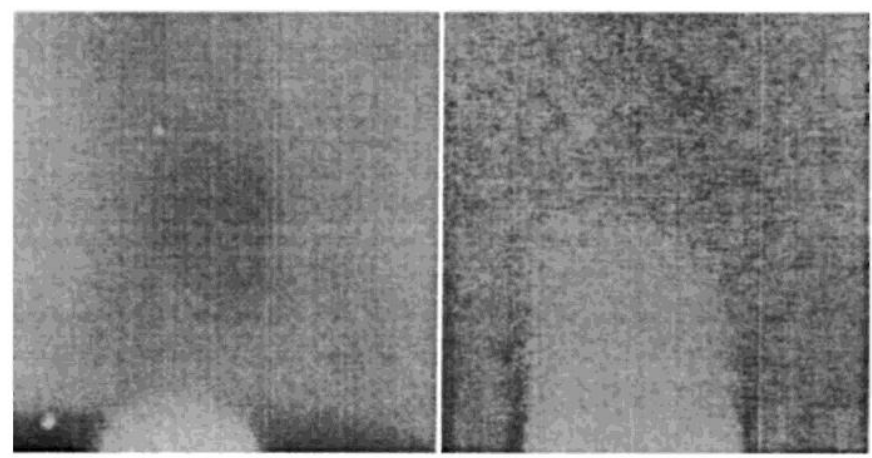

Figure 14. SKPFM of active head under $150 \mathrm{~nm}$ epoxy coating. Left: topography (full scale range of 2 $\mu \mathrm{m}$ ). Right: potential (full scale range of $0.1 \mathrm{~V}$ ). Area of scan is $80 \times 80 \mu \mathrm{m}$.

Table I. Physical characteristics of filaments and calculated corrosion kinetics.

\begin{tabular}{lrr} 
& \multicolumn{2}{c}{ Coating thickness $(\mathrm{nm})$} \\
\cline { 2 - 3 } & \multicolumn{1}{c}{150} & \multicolumn{1}{c}{300} \\
\hline Filament average width $(\mathrm{cm})$ & $1.4 \times 10^{-2}$ & $2 \times 10^{-2}$ \\
Depth of attack $(\mathrm{cm})$ & $7 \times 10^{-5}$ & $3 \times 10^{-5}$ \\
Propagation rate $(\mathrm{cm} / \mathrm{s})$ & $4 \times 10^{-7}$ & $7 \times 10^{-7}$ \\
Active head area $\left(\mathrm{cm}^{2}\right)$ & $1.7 \times 10^{-4}$ & $0.65 \times 10^{-4}$ \\
Rate of Fe dissolution $(\mathrm{mol} / \mathrm{s})$ & $5.5 \times 10^{-14}$ & $5.9 \times 10^{-14}$ \\
Anodic current density $\left(\mathrm{A} / \mathrm{cm}^{2}\right)$ & $2.5 \times 10^{-4}$ & $1.54 \times 10^{-4}$ \\
Cathodic current density associated & $2.5 \times 10^{-4}$ & $1.2 \times 10^{-4}$ \\
with oxygen diffusion through coating & & \\
$\left(\mathrm{A} / \mathrm{cm}^{2}\right)$ & &
\end{tabular}


$\mathrm{A} / \mathrm{cm}^{2}$ for 150 and $300 \mathrm{~nm}$ coatings, respectively. For the $150 \mathrm{~nm}$ coating, the anodic dissolution current density associated with filament propagation is identical to the cathodic current density associated with oxygen diffusion through the coating. Because diffusion through the coating is sufficient to support the rate of filament propagation, the filaments tend to grow radially, resulting in a bead appearance. As the thickness of the film increases, the amount of oxygen that can be supplied by diffusion through the coating decreases. For the $300 \mathrm{~nm}$ coating, the rate of corrosion is greater than the rate of oxygen diffusing through the coating, and oxygen transport through the tail or through the voids along the tail is required. The respective contribution of the tail and voids to oxygen transport is difficult to calculate because the nature of the hydrated compounds in the tail and particularly the porosity and water content are not known precisely. The cross-sectional area of the tail (about $4 \times 10^{-6} \mathrm{~cm}^{2}$ ) is about 200 times larger than that of the voids (about $\left.2 \times 10^{-8} \mathrm{~cm}^{2}\right)$. However, diffusion of $\mathrm{O}_{2}$ in air $\left(0.21 \mathrm{~cm}^{2} / \mathrm{s}\right)$ is extremely fast. The contribution of cathodic current from the reduction of oxygen transported through the tails or side voids changes the morphology for filaments under the thicker film to be more linear or worm-like. The relative contribution of oxygen transported through the coating is expected to be low for a thicker coating, which is more typical of standard paint applications.

\section{Conclusions}

SKPFM was successfully used to study FFC of 1045 steel underneath thin epoxy coatings. The following conclusions were made.

1. Volta potentials measured on the surface of the polymer were related to the practical nobility of the underlying substrate. The lateral resolution through a $150 \mathrm{~nm}$ film was estimated at $5 \mu \mathrm{m}$.

2. FFC of steel under $300 \mathrm{~nm}$ epoxy coatings revealed a clear separation of local active anodes and cathodes in the head, whereas the tail had a uniform high potential. Anodic activity was not restricted to the front edge, as previously described in the literature. Cathodic activity was observed in the vicinity of the anodes and also on the periphery of the head extending outward, suggesting that cathodic disbondment is responsible in part for coating delamination ahead of the advancing filament.

3. The morphology of the filaments under a $150 \mathrm{~nm}$ thick epoxy coating was like strings of beads rather than worm-like. Anodes and cathodes were not distinguished in Volta potential maps of the head.

4. Continuous voids or channels were identified along the edge of filament tails as a result of a loss of adherence of the coating. These voids likely provide fast access of oxygen to the head.

5. For thick coatings, oxygen transported through these voids dominates oxygen transported by diffusion through the epoxy coating. For thin films, the rate of oxygen diffusion through the epoxy coating increases, and oxygen reduction activity is distributed uniformly around the active dissolution site, not only at the back of the anode as in thicker films, resulting in a mixed radial-directional growth of the filaments.

\section{Acknowledgments}

Funding for this effort has been provided under the Corrosion Measurement and Control project of the 
National Defense Center for Environmental Excellence (NDCEE), which is operated under Army contract DAAE30-98-C-1050 by Concurrent Technologies Corporation. The authors are indebted to John Escarsega for providing information about epoxy coatings.

The Ohio State University assisted in meeting the publication costs of this article.

\section{References}

1. R. T. Ruggeri and T. R. Beck, Corrosion (Houston), 39, 452 (1983).

2. A. Bautista, Prog. Org. Coat., 28, 49 (1996).

3. M. J. Schofield, J. D. Scantlebury, G. C. Wood, and J. B. Johnson, Proceedings of the 8th International Congress on Metallic Corrosion, Mainz, Germany, 1047, (Sept 1981).

4. G. M. Hoch, Localized Corrosion, Williamsburg, Virginia, 1971, R. S. Staehle, B. F. Brown, J. Kruger, and A.Agrawal, Editors, p. 134, NACE, Houston, TX (1974).

5. H. Kaesche, Werkst. Korros., 11, 668 (1959).

6. M. Van Loo, D. D. Laiderman, and R. R. Bruhn, Corrosion (Houston), 9, 277 (1953).

7. W. Funke, Ind. Eng. Chem. Process Des. Dev., 24, 343 (1985).

8. W. H. Slabaugh and M. Grotheer, Ind. Eng. Chem., 46, 1014 (1954).

9. M. Stratmann and H. Streckel, Corros. Sci., 30, 681 (1990).

10. M. Stratmann and H. Streckel, Werkst. Korros., 43, 316 (1992).

11. N. Le Bozec, D. Persson, A. Nazarov, and D. Thierry, J. Electrochem. Soc., 149, B403 (2002).

12. W. Schmidt and M. Stratmann, Corros. Sci., 40, 1441 (1998).

13. G. Williams and H. N. McMurray, J. Electrochem. Soc., 148, B377 (2001).

14. G. Williams, H. N. McMurray, D. Hayman, and S. O'Driscoll, Phys. Chem. Comm., 6, 1 (2001).

15. H. N. McMurray and G. Williams, J. Appl. Phys., 91, 1973 (2002).

16. G. Williams and H. N. McMurray, J. Electrochem. Soc., 150, B380 (2003).

17. G. Grundmeier, W. Schmidt, and M. Stratmann, Electrochim. Acta, 45, 2515 (2000).

18. P. Schmutz and G. S. Frankel, J. Electrochem. Soc., 145, 2295 (1998).

19. P. Schmutz and G. S. Frankel, J. Electrochem. Soc., 145, 2285 (1998).

20. P. Schmutz and G. S. Frankel, J. Electrochem. Soc., 146, 4461 (1999).

21. P. Leblanc and G. S. Frankel, J. Electrochem. Soc., 149, B239 (2002).

22. E. Hornung, M. Rohwerder, and M. Stratmann, Electrochim. Acta, 48, 1235 (2003).

23. S. Yee, R. A. Oriani, and M. Stratmann, J. Electrochem. Soc., 138, 55 (1991).

24. A. Leng, H. Streckel, and M. Stratmann, Corros. Sci., 41, 547 (1999).

25. K. Doblhofer, Bull. Electrochem., 8, 96 (1992).

26. V Guillaumin, P. Schmutz, and G. S. Frankel, J. Electrochem. Soc., 148, B163 (2001).

27. O. Ø. Knudsen and U. Steinsmo, in Advances in Corrosion Protection by Organic Coatings, Vol. 2, Paper 37, Cambridge, U.K., Sept 1999; http://www2.umist.ac.uk/ corrosion/JCSE/Volume2/Paper37/v2p37.html 